\title{
Phosphate Adsorption on Zirconium-Loaded Activated Carbon, and its Application for Phosphate Recovery from Deep Seawater
}

\author{
Takaaki Wajima
}

\begin{abstract}
The adsorption of phosphate onto zirconium-loaded activated carbon $(\mathrm{Zr}-\mathrm{AC})$ was studied, and phosphate was recovered from deep seawater using the $\mathrm{Zr}$-AC. The $\mathrm{Zr}$-AC complex was prepared by mixing activated carbon with a zirconyl nitrate solution. The amount of phosphate that adsorbed onto the $\mathrm{Zr}$-AC depended on the $\mathrm{pH}$ of the solution.

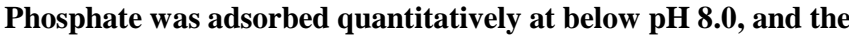
amount adsorbed decreased as the $\mathrm{pH}$ increased. $\mathrm{Zr}$-AC was found to adsorb phosphate from seawater almost as efficiently as from an aqueous solution made with distilled water. The equilibrium adsorption capacity of the $\mathrm{Zr}$ - $\mathrm{AC}$ for phosphate in seawater was measured and extrapolated using the Langmuir and Freundlich isotherm models. The Langmuir model fitted the experimental data better than did the Freundlich model, and the calculated maximum adsorption capacity for phosphate was $0.64 \mathrm{mmol} / \mathrm{g}$. Phosphate was recovered from deep seawater using a chromatographic selective recovery process using a packed-bed column. The results showed that phosphate was selectively adsorbed in the adsorption step, and the phosphate could be recovered and concentrated into a $\mathrm{NaOH}$ solution in the desorption step. The adsorbent in the column was able to be repeatedly used to recover phosphate from seawater.
\end{abstract}

Index Terms-Column test, deep seawater, phosphate recovery, Zirconium-loaded activated carbon.

\section{INTRODUCTION}

Phosphorus plays key roles in sustaining the production of food, animal feed, and biofuels and is used in industrial applications. Phosphorus is generally applied to agricultural soils in fertilizers that are produced from phosphate rocks. However, global supplies of phosphate rocks are limited [1]-[3]. Currently, 178.5 Mt of phosphate rock, equivalent to $23 \mathrm{Mt}$ of phosphorus, is mined every year, and $90 \%$ of the rock is used in the production of food (approximately $82 \%$ is used as fertilizer and approximately $7 \%$ is used in animal feed additives) [4]. Increased demand for food and animal feed mean that phosphate rock is expected to become increasingly scarce and expensive in future [1]. Phosphate rock deposits are very unequally distributed, and only three countries (China, Morocco, and the United States) control more than $85 \%$ of deposits [5]. The control of phosphate rock deposits may cause severe geopolitical problems by affecting the availability of phosphorus fertilizers and regional food

Manuscript received March 25, 2016, revised August 8, 2016. This work was supported by the Cooperative Research Program of the Institute of Ocean Energy, Saga University (15003A)

Takaaki Wajima is with the Department of Urban Environment Systems, Graduate School of Engineering, Chiba University, Japan (e-mail: wajima@tu.chiba-u.ac.jp). production and food security [6]. It is important to develop new techniques and economic opportunities for recovering phosphorus to ensure the long-term sustainability of food production.

Efficiently using phosphorus fertilizers in agriculture and recovering and recycling phosphorus in wastewater, natural water, and waste materials will be key to increasing the time global phosphorus reserves will last. Releases of phosphorus to groundwater and surface water have already caused serious eutrophication problems around the world, and these problems negatively affect the abilities of many aquatic species to survive and decrease the safety of drinking water supplies [7], [8]. It has been found that phosphorus concentrations higher than $0.02 \mathrm{mg} / \mathrm{L}$ in lake water can generally accelerate eutrophication [9], [10]. Treatments to remove phosphorus from water have therefore been studied extensively [11]-[13]. A wide range of methods for treating phosphorus pollution, involving adsorption, chemical precipitation, biological processes, electrodialysis, ion exchange, and reverse osmosis, have been developed and applied [14]-[17]. Methods involving adsorption are promising because they are simple, effective, easily used in practice, appropriate for low phosphorus concentrations, and can allow the phosphorus that is removed to be recovered [8].

Adsorbents have been developed for removing phosphate, and they have been used in practical applications. The sorption of phosphate has been investigated in many studies using many sorbents, but very few studies of the influences of major electrolytes present in natural fresh water on the uptake of phosphate by sorbents have been performed [18]-[20]. Similarly, only a few studies have been performed on the influences of electrolytes in seawater on the uptake of phosphate by sorbents such as goethite [21], [22], manganese dioxide [23], aluminum oxide hydroxide [24], layered double hydroxide [25], La(III)-Chelex resin [26], and aluminum [27]. Hydrous zirconium oxide has been found to be remarkably selective for phosphoric ions [28] and to be very resistant to acids, alkalis, oxidants, and reductants [29]. In previous studies [18], [30], [31], it has been found that zirconium oxide has a high adsorption capacity for phosphorus and can be used to remove phosphorus from water. However, pure zirconium oxide is relatively expensive, so using it to remove phosphorus from water is not cost-effective. Zirconium-loaded materials with high phosphate affinities have therefore been prepared. Such materials are prepared by loading zirconium onto materials such as activated carbon (AC) [32], resin [33], wheat straw [34], orange waste gel [35], [36], and okara [37], [38]. 
In this study, zirconium-loaded $\mathrm{AC}(\mathrm{Zr}-\mathrm{AC})$ was prepared with the aim of using it to recover phosphate from deep seawater. $\mathrm{Zr}$-AC was prepared because AC is a popular material for loading with metals. Deep seawater (at depths of between about $500 \mathrm{~m}$ and $1000 \mathrm{~m}$ ) circulates around the world. Deep seawater is clean and rich in mineral components, especially nutrients such as nitrate, phosphate, and silicate, compared with surface seawater. Attempts to use deep seawater in many ways have been made [39]. Japan is surrounded by seas and the ocean, and developing ocean resources could bring benefits to Japan. However, to the best of our knowledge, the recovery of phosphate in deep seawater using $\mathrm{Zr}-\mathrm{AC}$ has not previously been studied. An original study of the effectiveness of $\mathrm{Zr}-\mathrm{AC}$ at selectively recovering phosphate from deep seawater is described here.

\section{EXPERIMENTAL}

\section{A. Preparation of $\mathrm{Zr}-\mathrm{AC}$}

The $\mathrm{Zr}$-AC complex was prepared by adding $\mathrm{AC}$ to a zirconyl nitrate solution (with a zirconium concentration of 20 $\mathrm{g} / \mathrm{L}$ ). Two types of commercial AC, powdered AC (Wako Pure Chemical Industries, Osaka, Japan) and granular AC with a granule diameter of $0.5 \mathrm{~mm}$ (Kureha, Tokyo, Japan), were used. AC (10 g) was purified by adding it to $3 \mathrm{M}$ aqueous hydrochloric acid and stirring the mixture at $25^{\circ} \mathrm{C}$ for $1 \mathrm{~d}$. The mixture was then filtered, and the $\mathrm{AC}$ was added to a zirconyl nitrate solution. The mixture was stirred for $3 \mathrm{~d}$, washed with distilled water, then dried in a drying oven for $2 \mathrm{~d}$. The crystalline phases of the $\mathrm{Zr}$-AC were analyzed by X-ray diffractometry using a Mini-flex 600 instrument (Rigaku, Tokyo, Japan).

\section{B. Phosphate Adsorption Properties of the $\mathrm{Zr}$-AC}

The phosphate adsorption properties of $\mathrm{Zr}-\mathrm{AC}$ were investigated by performing tests using powdered $\mathrm{Zr}-\mathrm{AC}$.

The adsorption of phosphate by $\mathrm{Zr}-\mathrm{AC}$ was investigated at different $\mathrm{pH}$ values. A series of $1 \mathrm{mM} \mathrm{NaH}{ }_{2} \mathrm{PO}_{4}$ solutions were prepared at $\mathrm{pH}$ values between $\mathrm{pH} 3$ and $\mathrm{pH} 12$ (the initial $\mathrm{pH}$ was adjusted by adding $\mathrm{HCl}$ or $\mathrm{NaOH}$ ). A $0.1 \mathrm{~g}$ aliquot of the $\mathrm{Zr}-\mathrm{AC}$ sample was added to a $20 \mathrm{~mL}$ aliquot of a phosphate solution in a centrifuge tube $(50 \mathrm{~mL})$ at room temperature, and the tube was shaken for $12 \mathrm{~h}$ using a reciprocal shaker. The mixture was then centrifuged, and the aqueous phase was separated from the solid phase. The $\mathrm{pH}$ of the supernatant was measured using a $\mathrm{pH}$ meter (a LAQUA F-72 pH/ion meter; Horiba, Kyoto, Japan). The phosphate concentration in the supernatant was determined using the molybdenum blue method. The amount of phosphate that had been adsorbed, $q(\mathrm{mmol} / \mathrm{g})$, was calculated using the equation

$$
q=\left(C_{0^{-}} C\right) \cdot V / w
$$

where $C_{0}$ and $C$ are the concentrations ( $\mathrm{mmol} / \mathrm{L}$ ) of phosphate ions in the initial solution and sampling solution, respectively, $V$ is the volume $(\mathrm{L})$ of the solution, and $w$ is the mass $(\mathrm{g})$ of $\mathrm{Zr}-\mathrm{AC}$ added.

The adsorption capacities of $\mathrm{Zr}-\mathrm{AC}$ at different initial phosphate concentrations and salinities were determined. Solutions containing $\mathrm{NaH}_{2} \mathrm{PO}_{4}$ at between 1 and $20 \mathrm{mM}$, in distilled water or seawater were tested. Seawater was collected from the surface water layer in Imari Bay, Saga Prefecture, Japan. The chemical composition and the $\mathrm{pH}$ of the seawater are shown in Table I. A $0.1 \mathrm{~g}$ aliquot of $\mathrm{Zr}$-AC was added to $20 \mathrm{~mL}$ of a test solution in a centrifuge tube $(50$ $\mathrm{mL}$ ) at room temperature, and the tube was shaken for $12 \mathrm{~h}$ using a reciprocal shaker. The mixture was then centrifuged, and the aqueous phase was separated from the solid phase, then the $\mathrm{pH}$ of the supernatant was measured using a $\mathrm{pH}$ meter. The phosphate concentration in the supernatant was determined using the molybdenum blue method. The amount of phosphate that was adsorbed, $q(\mathrm{mmol} / \mathrm{g})$, was then calculated.

\section{Column Test Using Deep Seawater}

Chromatographic experiments were performed using deep seawater, using Zr-AC packed in a column as shown in Fig. 1. The deep seawater was purchased from Koshiki Deep Ocean Water Co. (Kagoshima, Japan). The chemical composition and $\mathrm{pH}$ of the deep seawater are shown in Table I. The deep seawater contained $0.0015 \mathrm{mmol} / \mathrm{L}$ phosphate, and the other elements were found at almost the same concentrations in the deep seawater as in the seawater. Granular $\mathrm{Zr}-\mathrm{AC}(0.2 \mathrm{~g})$ was packed into a column to a depth of $3 \mathrm{~cm}$ (the volume of the wet product was $0.07 \mathrm{~cm}^{3}$ ) sandwiched between layers of quartz wool. Distilled water was passed through the column to prepare it for use. Deep seawater was then passed upward through the column at a flow rate of $5.0 \mathrm{~mL} / \mathrm{min}$. The deep seawater was supplied to the column using a ceramic pump. The effluent was collected using a fraction collector, and the phosphate concentration in each fraction was determined using the molybdenum blue method.

The desorption of phosphate from $\mathrm{Zr}$-AC that had been loaded with phosphate in an adsorption test using deep seawater was studied. The seawater in the loaded $\mathrm{Zr}-\mathrm{AC}$ in the column was washed out by passing distilled water through the column. The phosphate was then desorbed by passing 2.5 $\mathrm{mol} / \mathrm{L} \mathrm{NaOH}_{(\mathrm{aq})}$ upward through the column at a flow rate of $5.0 \mathrm{~mL} / \mathrm{min}$. The $\mathrm{NaOH}$ solution was supplied to the column using a ceramic pump. The effluent was collected using a fraction collector, and the phosphate concentration in each fraction was determined using the molybdenum blue method.

The bed volume of the column, $B V$, was calculated using the equation

$$
B V=v \cdot t / V
$$

where $v$ is the flow rate of the solution $(\mathrm{mL} / \mathrm{min}), t$ is the time the feed solution was supplied ( $\mathrm{min}$ ), and $V$ is the volume of the wet product $(\mathrm{mL})$.

TABLE I: CHEMICAL COMPOSITION AND PH OF THE SEAWATER (SW) AND DEEP SEAWATER (DSW)

\begin{tabular}{ccccccccc}
\hline \hline & \multicolumn{7}{c}{ Chemical and concentration (mmol/L) } & \multirow{2}{*}{$\mathrm{pH}$} \\
\cline { 2 - 7 } & $\mathrm{Na}^{+}$ & $\mathrm{K}^{+}$ & $\mathrm{Mg}^{2+}$ & $\mathrm{Ca}^{2+}$ & $\mathrm{Cl}^{-}$ & $\mathrm{SO}_{4}{ }^{2-}$ & $\mathrm{P}$ & \\
\hline SW & 468 & 9 & 52 & 9 & 472 & 26 & N.D. & 7.4 \\
DSW & 491 & 10 & 57 & 8 & 462 & 29 & 0.0015 & 8.0 \\
\hline \hline
\end{tabular}

\section{Regeneration and Reuse of the Adsorbent}

A regeneration experiment was performed using a column 
packed with granular $\mathrm{Zr}-\mathrm{AC}$, using a $1 \mathrm{mM} \mathrm{NaH} \mathrm{PO}_{4}$ solution in seawater. Granular Zr-AC (0.5 g) was packed into a column to a depth of $5 \mathrm{~cm}$ (the volume of the wet product was 0.22 $\mathrm{cm}^{3}$ ) sandwiched between layers of quartz wool. Distilled water was passed through the column to prepare it for use. The seawater containing $1 \mathrm{mmol} / \mathrm{L} \mathrm{NaH}_{2} \mathrm{PO}_{4}$ was then passed upward through the column at a flow rate of $5.0 \mathrm{~mL} / \mathrm{min}$. The seawater was supplied to the column using a ceramic pump. The effluent was collected using a fraction collector, and the phosphate concentration in each fraction was determined using the molybdenum blue method. After equilibrium had been achieved, the seawater in the column was washed out by passing distilled water through the column. The phosphate was then desorbed by passing $0.1 \mathrm{mmol} / \mathrm{L} \mathrm{NaOH}_{(\mathrm{aq})}$ upward through the column at a flow rate of $2.0 \mathrm{~mL} / \mathrm{min}$. The $\mathrm{NaOH}$ solution was supplied to the column using a ceramic pump. The effluent was collected using a fraction collector, and the phosphate concentration in each fraction was determined using the molybdenum blue method. After the phosphate had been desorbed, the column was washed by pumping distilled water through the column for 30 min until the effluent had a neutral $\mathrm{pH}$. The regenerated bed was used in another sorption cycle, and five adsorption-desorption cycles were performed in total.

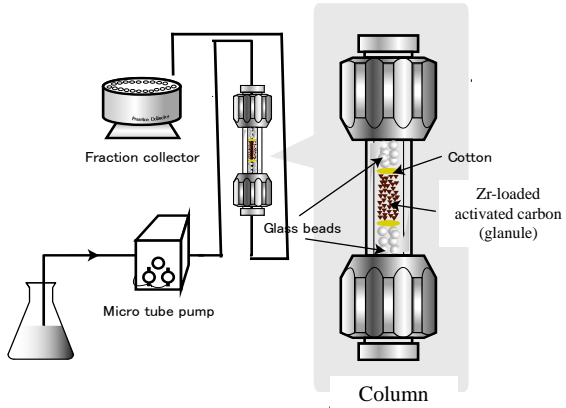

Fig. 1. Schematic of the adsorption and desorption column apparatus.

\section{RESULTS AND DISCUSSION}

\section{A. Adsorption of Phosphate by $\mathrm{Zr}-\mathrm{AC}$}

The X-ray diffractometry patterns of the AC and $\mathrm{Zr}$-AC are shown in Fig. 2. No crystalline phases were found in the AC or $\mathrm{Zr}-\mathrm{AC}$, indicating that no crystalline structures formed when $\mathrm{Zr}$ was loaded onto the AC.

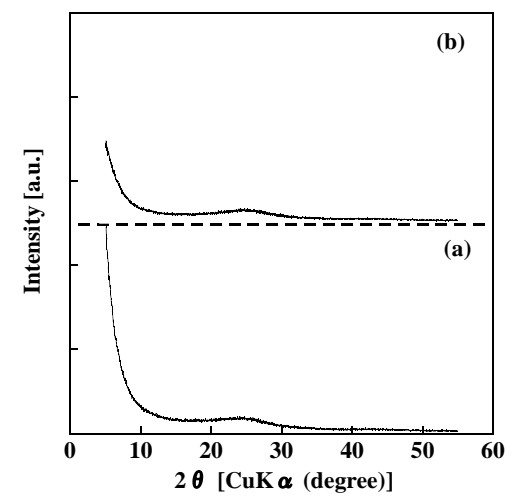

Fig. 2. X-ray diffractometry patterns of (a) the activated carbon and (b) the zirconium-loaded activated carbon.

The $\mathrm{pH}$ of an aqueous solution will have important effects on the processes involved in the recovery of phosphate. The
$\mathrm{pH}$ values when equilibrium had been reached in tests performed at different initial $\mathrm{pH}$ values are shown in Fig. 3. The equilibrium $\mathrm{pH}$ was lower than the initial $\mathrm{pH}$ in each test, especially when the initial $\mathrm{pH}$ was around 10 , indicating that $\mathrm{Zr}-\mathrm{AC}$ is weakly acidic. Seawater generally has a $\mathrm{pH}$ of around 8 , so seawater from which phosphate has been removed using $\mathrm{Zr}-\mathrm{AC}$ will have a $\mathrm{pH}$ of approximately 6 .

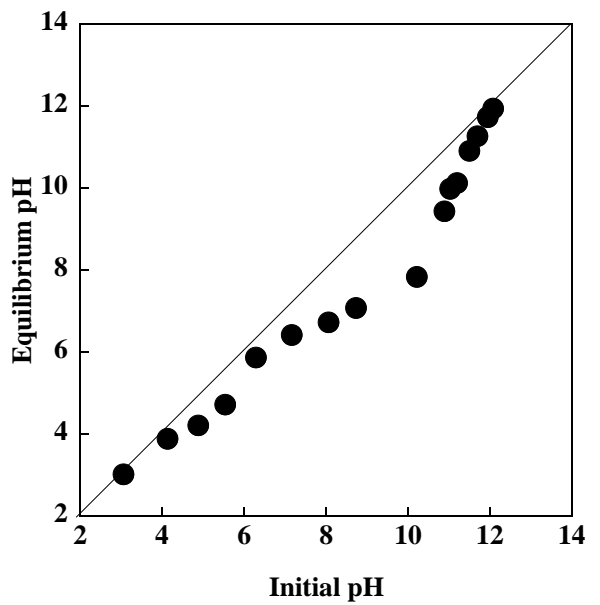

Fig. 3. Initial $\mathrm{pH}$ and $\mathrm{pH}$ after equilibrium had been reached when phosphate was removed from solutions with different initial $\mathrm{pH}$ values using the zirconium-loaded activated carbon.

The amounts of phosphate adsorbed onto $\mathrm{Zr}-\mathrm{AC}$ in phosphate solutions at different $\mathrm{pH}$ values are shown in Fig. 4. It can be seen that $0.2 \mathrm{mmol}$ of phosphate was removed per gram of $\mathrm{Zr}-\mathrm{AC}$ at below $\mathrm{pH} 6$, and the amount of phosphate adsorbed decreased as the $\mathrm{pH}$ increased. It was concluded that $\mathrm{Zr}-\mathrm{AC}$ can adsorb phosphate from acidic and neutral solutions and release phosphate to alkali solutions.

Our results showed that $\mathrm{Zr}-\mathrm{AC}$ could adsorb phosphate from seawater because the $\mathrm{Zr}-\mathrm{AC}$, being acidic, would cause the seawater $\mathrm{pH}$ to decrease to 6 . Our results also showed that the phosphate could be desorbed from the $\mathrm{Zr}$-AC using an alkaline solution.

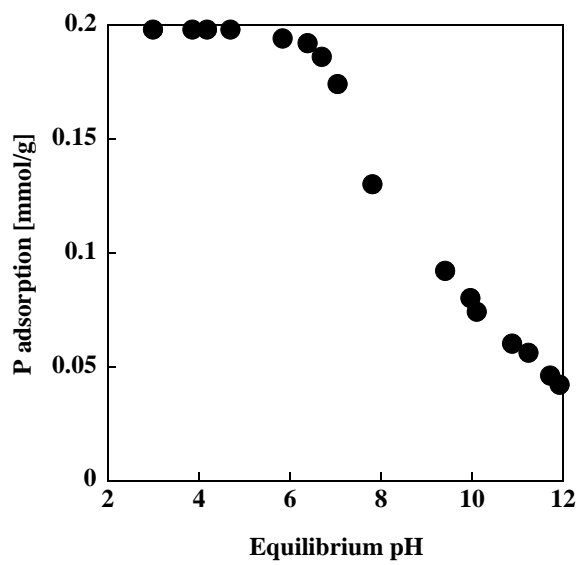

Fig. 4. Amount of phosphate adsorbed from solution per gram of zirconium-loaded activated carbon at different equilibrium $\mathrm{pH}$ values.

The phosphate adsorption isotherms for the $\mathrm{AC}$ and $\mathrm{Zr}-\mathrm{AC}$ for solutions in distilled water and seawater are shown in Fig. 5. The amount of phosphate adsorbed per gram of $\mathrm{Zr}-\mathrm{AC}$ increased to approximately $0.6 \mathrm{mmol} / \mathrm{g}$ and then remained almost constant as the equilibrium concentration increased, whereas almost no phosphate was adsorbed per gram of AC. 
The adsorption of phosphate in distilled water and seawater followed almost the same behavior. These results indicate that the $\mathrm{Zr}$-AC had a higher adsorption capacity for phosphate than did the AC, and that the $\mathrm{Zr}$-AC could adsorb phosphate as effectively from seawater as from distilled water.

The adsorption data for phosphate in distilled water and seawater were assessed using isotherm models. Several isotherm models for describing equilibrium sorption distributions are available, and the Langmuir and Freundlich models are commonly fitted to experimental data. The linear form of the Langmuir model is shown in (3), and the linear form of the Freundlich model is shown in (4).

$$
\begin{gathered}
C_{e} / q_{e}=1 /\left(Q_{\max } \bullet K_{L}\right)+C_{e} / Q_{\max } \\
\ln \left(q_{e}\right)=\ln \left(K_{F}\right)+(1 / n) \bullet \ln \left(C_{e}\right)
\end{gathered}
$$

In (3) and (4), $q_{e}$ is the amount of phosphate adsorbed at equilibrium $(\mathrm{mmol} / \mathrm{g}), Q_{\max }(\mathrm{mmol} / \mathrm{g})$ and $K_{L}(\mathrm{~L} / \mathrm{mg})$ are Langmuir constants related to the maximum adsorption capacity (corresponding to the complete coverage of available adsorption sites) and a measure of the adsorption energy (equilibrium adsorption constant), respectively, and $K_{F}$ and $n$ are Freundlich constants.

The Langmuir and Freundlich constants and the regression coefficients for the adsorption of phosphate are given in Table II. The correlation coefficients $\left(R^{2}\right)$ indicated that the Langmuir model fitted the data better than did the Freundlich model for solutions in distilled water and solutions in seawater. The maximum adsorption capacity of $\mathrm{Zr}$ - $\mathrm{AC}$ for phosphate in seawater, calculated using the Langmuir model, was found to be $0.64 \mathrm{mmol} / \mathrm{g}$.

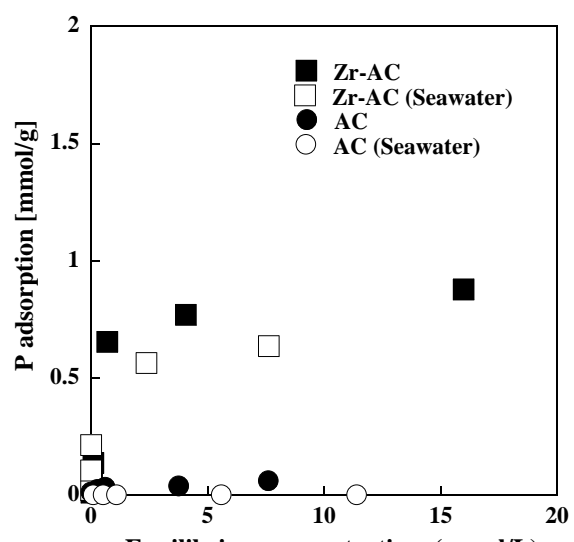

Equilibrium concentration $(\mathrm{mmol} / \mathrm{L})$

Fig. 5. Isotherms for the adsorption of phosphate from distilled water and seawater by the activated carbon and zirconium-loaded activated carbon.

TABLE II: ISOTHERM PARAMETERS FOR THE ADSORPTION OF PHOSPHATE BY THE ZIRCONIUM-LOADED ACTIVATED CARBON

\begin{tabular}{ccccccc}
\hline \hline & \multicolumn{3}{c}{ Langmuir parameters } & \multicolumn{3}{c}{ Freundlich parameters } \\
\hline & $Q_{\max }$ & $K_{L}$ & $R^{2}$ & $K_{F}$ & $N$ & $R^{2}$ \\
\hline Distilled water & 0.92 & 1.32 & 0.996 & 1.69 & 0.33 & 0.826 \\
Seawater & 0.64 & 6.72 & 0.998 & 5.95 & 0.47 & 0.996 \\
\hline \hline
\end{tabular}

\section{B. Chromatographic Separation and Recovery of Phosphate}

A chromatographic test was performed. First, deep seawater was used as a feed solution. The profile for the adsorption of phosphate from deep seawater is shown in Fig. 6(a). The phosphate concentration gradually increased and reached $1.5 \mu \mathrm{mol} / \mathrm{L}$ at $>80000$ bed volumes. The profile for the desorption of phosphate from the adsorbent (into aqueous $\mathrm{NaOH}$ ) is shown in Fig. 6(b). The results indicate that phosphate was easily desorbed from $\mathrm{Zr}-\mathrm{AC}$ and could be recovered quickly (at $<2000$ bed volumes). Phosphate in deep seawater was able to be recovered using $\mathrm{Zr}$-AC. In the experiment, $0.0936 \mu \mathrm{mol}$ of phosphate was collected and the phosphate concentration was 12 times higher in the desorbed solution than in the deep seawater.
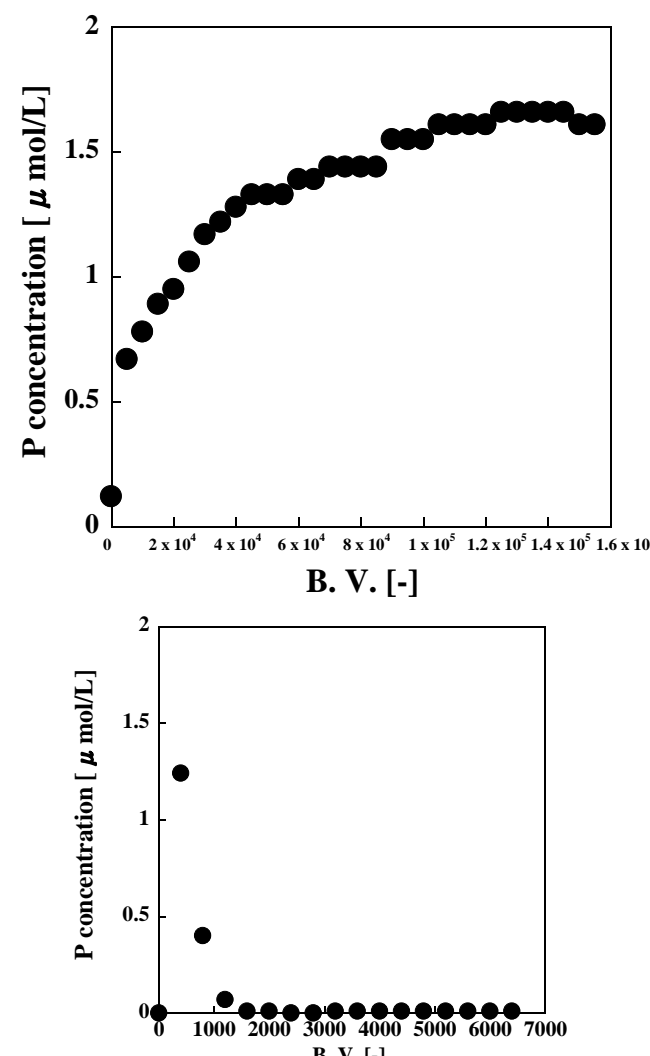

B. V. [-]

Fig. 6. Curves for the (a) adsorption and (b) desorption of phosphate in deep seawater by zirconium-loaded activated carbon (B.V. = bed volumes).

The adsorption and desorption curves for the five adsorption-desorption cycles are shown in Fig. 7. The amount adsorbed followed a similar trend in every cycle, increasing sharply at the beginning of the process and then reaching a constant value at $<100$ bed volumes. The amount desorbed increased rapidly at $<50$ bed volumes, then decreased gradually. The adsorption and desorption breakthrough times were almost the same. In the first cycle, $14.51 \mathrm{mmol}$ of phosphate (as phosphorus) was desorbed from the $\mathrm{Zr}-\mathrm{AC}$, and in the second to fifth cycles $3.7-5.5 \mathrm{mmol}$ of phosphate (as phosphorus) was desorbed. The phosphate concentration in the desorbed solution in the first cycle was 65 times higher than the phosphate concentration in the initial phosphate solution, whereas the phosphate concentrations in the desorbed solutions in the second to fifth cycles were 17-25 times higher than the phosphate concentration in the initial phosphate solution. More phosphate was recovered in the first cycle than in the later cycles. It is possible that some of the zirconium, which would have been weakly bound to the AC, was eluted in the first cycle. However, no significant losses were found after the second cycle, so the $\mathrm{Zr}$-AC could 
be used repeatedly to recover phosphate from seawater.
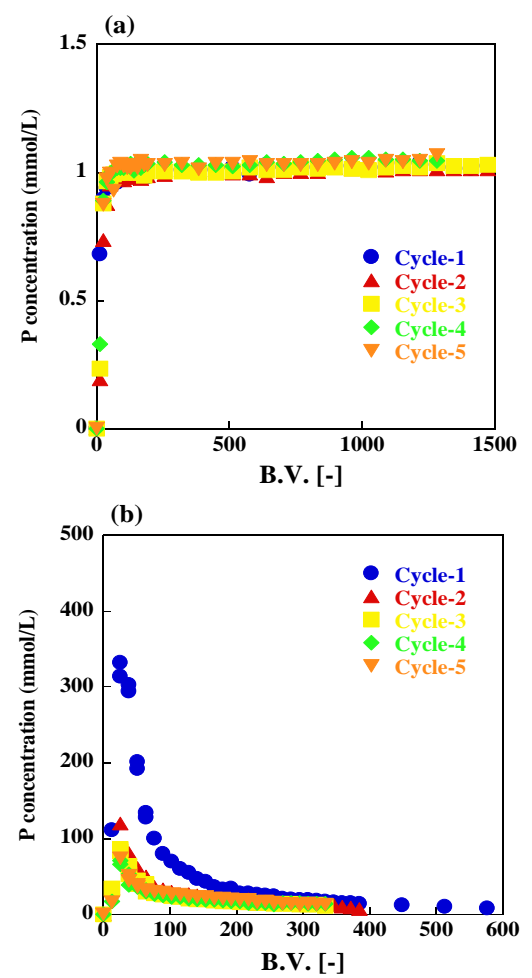

Fig. 7. Curves for the (a) adsorption and (b) desorption of phosphate from seawater containing $1 \mathrm{mmol} / \mathrm{L}$ phosphate in five adsorption-desorption cycles.

\section{CONCLUSIONS}

A novel adsorbent, $\mathrm{Zr}$-AC, was used to attempt to selectively adsorb phosphate from seawater. The adsorption of phosphate onto the $\mathrm{Zr}$-AC was studied to determine whether phosphate could be recovered from deep seawater. Zirconium could be loaded onto AC by mixing the AC with a solution of zirconyl nitrate, and the $\mathrm{Zr}$-AC produced could adsorb phosphate from seawater. $\mathrm{Zr}$-AC could very selectively adsorb phosphate from seawater. The Langmuir model fitted the experimental isotherm data better than did the Freundlich model, and the calculated maximum adsorption capacity for phosphate was $0.64 \mathrm{mmol} / \mathrm{g}$. The $\mathrm{Zr}$-AC could adsorb phosphate from acidic and neutral solutions and release phosphate into alkaline solutions. The selective recovery of phosphate from deep seawater using a chromatographic technique was studied, and it was found that phosphate could be selectively adsorbed from deep seawater in the adsorption step and recovered and concentrated into aqueous $\mathrm{NaOH}$ in the desorption step. A column packed with $\mathrm{Zr}-\mathrm{AC}$ could be used for repeated adsorption-desorption cycles.

\section{ACKNOWLEDGMENT}

This work was supported by the Cooperative Research Program of the Institute of Ocean Energy, Saga University (15003A).

\section{REFERENCES}

[1] D. Cordell, J.O. Drangert, and S. White, "The story of phosphorus: Global food security and food for thought," Global Environ. Change, vol. 19, pp. 292-305, May 2009.
[2] V. Smil, "Phosphorus in the environment: Natural flows and human interfaces," Аnпu. Rev. Energy Environ., vol. 25, pp. 53-88, Nov. 2000.

[3] D. Cordell, A. Rosemarin, J. J. Schröder, and A. L. Smit, "Toward global phosphorus security: A systems framework for phosphorus recovery and reuse options," Chemosphere, vol. 84, pp. 747-758, Aug. 2011.

[4] International Fertilizer Industry Association, Feeding the Earth Global Phosphate Rock Production Trends from 1961 to 2010: Reasons for the Temporary Setback in 1988-1994, Paris, France: International Fertilizer Industry Association, 2011.

[5] D. P. Van Vuuren, A. F. Bouwman, and A. H. W. Beusen, "Phosphorous demand for the 1970-2100 period: a scenario analysis of resource depletion," Global Environ. Policy, vol. 20, pp. 428-439, Aug. 2010.

[6] M. Dumas, E. Frossard, and R. W. Scholz, "Modeling biogeochemical processes of phosphorous for global food supply," Chemosphere, vol. 84, pp. 798-805, Aug. 2011.

[7] D. J. Conley et al., "Controlling eutrophication: Nitrogen and phosphorus," Science, vol. 323. pp. 1014-1015, Feb. 2009.

[8] P. Loganathan, S. Vigneswaran, J. Kandasamy, and N. S. Bolan, "Removal and recovery of phosphate from water using sorption," Crit. Rev. Environ. Sci. Technol., vol. 44, pp. 847-907, Aug. 2014.

[9] A. N. Sharpley et al., Agricultural Phosphorus and Eutrophication, $2^{\text {nd }}$ ed., United States Department of Agriculture, Agricultural Research Service Report 149, Washington D.C., USA: US Government Printing Office, 2003.

[10] R. J. Seviour, T. Mino, and M. Onuki, "The microbiology of biological phosphorus removal in activated sludge systems," FEMS Microbiol. Rev., vol. 27, pp. 99-127, Apr. 2003.

[11] L. E. Bashan and Y. Bashan, "Recent advances in removing phosphorus from wastewater and its future use as fertilizer," Water Res., vol. 38, pp. 4222-4246, Nov. 2004.

[12] H. B. Kwon et al., "Recycling waste oyster shells for eutrophication control," Resour. Conserv. Recy., vol. 41, pp. 75-82, Apr. 2004

[13] D. Brdjanovic et al., "Impact of excessive aeration on biological phosphorus removal from wastewater," Water Res., vol. 32, pp. 200-208, Jan. 1998.

[14] A. Oehmen et al., "Advances in enhanced biological phosphorus removal: from micro to macro scale," Water Res., vol. 41, pp. 2271-2300, Jun. 2007.

[15] E. Desmidt et al., "Global phosphorus scarcity and full-scale P-recovery techniques: a review," Crit. Rev. Environ. Sci. Technol., vol. 45, pp. 336-384, Aug. 2015.

[16] B. C. Pan et al., "New strategy to enhance phosphate removal from water by hydrous manganese oxide," Environ. Sci. Technol., vol. 48 , pp. 5101-5107, May 2014.

[17] W. Y. Huang et al., "Lanthanum-doped ordered mesoporous hollow silica spheres as novel adsorbents for efficient phosphate removal," $J$. Mater. Chem. A, vol. 2, pp. 8839-8848, May 2014.

[18] H. L. Liu, X. F. Sun, C. Q. Yin, and C. Hu, "Removal of phosphate by mesoporous $\mathrm{ZrO}_{2}$," J. Hazard. Mater., vol. 151, pp. 616-622, Mar. 2008.

[19] Y. J. Xue, G. B. Hou, and S. J. Zhu, "Characteristics and mechanisms of phosphate adsorption onto basic oxygen furnace slag," J. Hazard. Mater., vol. 162, pp. 973-980, Mar. 2009.

[20] R. Saad, K. Belkacemi, and S. Hamoudi, "Adsorption of phosphate and nitrate anions on ammonium-functionalized MCM-48: Effects of experimental conditions," J. Colloid Interface Sci., vol. 311, pp. 375-381, Jul. 2007.

[21] D. Hawke, P. D. Carpenter, and K. A. Hunter, "Competitive adsorption of phosphate on goethite in marine electrolytes," Environ. Sci. Technol., vol. 23, pp. 187-191, Feb. 1989.

[22] Y. Gao and A. Mucci, "Individual and competitive adsorption of phosphate and arsenate on goethite in artificial seawater," Chem. Geol., vol. 199, pp. 91-109, Aug. 2003.

[23] W. S. Yao and F. J. Millero, "Adsorption of phosphate on manganese dioxide in seawater," Environ. Sci. Technol., vol. 30, pp. 536-541, Jan. 1996.

[24] S. Tanada et al., "Removal of phosphate by aluminum oxide hydroxide," J. Colloid Interface Sci., vol. 257, pp. 135-140, Jan. 2003.

[25] R. Chitrakar et al., "Adsorption of phosphate from seawater on calcined MgMn-layered double hydroxides," J. Colloid Interface Sci., vol. 290, pp. 45-51, Oct. 2005.

[26] R. S. S. Wu, K. H. Lam, J. M. N. Lee, and T. C. Lau, "Removal of phosphate from water by a highly selective $\mathrm{La}$ (III)-Chelex resin," Chemosphere, vol. 69, pp. 289-294, Sep. 2007. 
[27] I. De Vincente, H. S. Jensen, and F. Ø. Andersen, "Factors affecting phosphate adsorption to aluminum in lake water: implications for lake restoration," Sci. Total Environ., vol. 389, pp. 29-36, Jan. 2008.

[28] E. Urnius, S. Klippenstein, and J. Protasiewicz, "Sterically promoted zirconium-phosphorus $\pi$-bonding: structural investigations of $\left[\mathrm{Cp}_{2} \mathrm{Zr}(\mathrm{Cl})\{\mathrm{P}(\mathrm{H}) \mathrm{Dmp}\}\right] \quad$ and $\left[\mathrm{Cp}_{2} \mathrm{Zr}\{\mathrm{P}(\mathrm{H}) \mathrm{Dmp}\}_{2}\right] \quad(\mathrm{Dmp}=2$, 6-Mes $\left.{ }_{2} \mathrm{C}_{6} \mathrm{H}_{3}\right)$," Inorg. Chim. Acta, vol. 297, pp. 181-190, Jan. 2000.

[29] T. M. Suzuki, J. O. Bomani, H. Matsunaga, and T. Yokoyama, "Preparation of porous resin loaded with crystalline hydrous zirconium oxide and its application to the removal of arsenic," React. Funct. Polym., vol. 43, pp. 165-172, Feb. 2000.

[30] R. Chitrakar et al., "Selective adsorption of phosphate from seawater and wastewater by amorphous zirconium hydroxide," J. Colloid Interface Sci., vol. 297, pp. 426-433, May 2006.

[31] S. Lee, B. C. Lee, K. Y. Lee, S. H. Lee and M. Iwamoto, "Phosphate sorption characteristics of zirconium meso-structure synthesized under different conditions," Environ. Technol., vol. 28, pp. 785-792, May 2007.

[32] A. Inoue, Y. Seike, and M. Okumura, "A simple determination of inorganic phosphorus compounds in environmental water based on their collection and separation using zirconium-loaded activated carbon,” Bunseki Kagaku, vol. 57, pp. 599-604, Aug. 2008.

[33] L. Chen et al., "Preferable removal of phosphate from water using hydrous zirconium oxide-based nanocomposite of high stability," $J$. Hazard. Mater., vol. 284, pp. 35-42, Mar. 2015.

[34] H. Qiu et al., "Fabrication of a biomass-based hydrous zirconium oxide nanocomposite for preferable phosphate removal and recovery," ACS Appl. Mater. Interfaces, vol. 7, pp. 20835-20844, Sep. 2015.

[35] B. K. Biswas et al., "Removal and recovery of phosphorus from water by means of adsorption onto orange waste gel loaded with zirconium," Bioresour. Technol., vol. 99, pp. 8685-8690, Dec. 2008.
[36] S. Ohura et al., "Phosphorus recovery from secondary effluent and side-stream liquid in a sewage treatment plant using zirconium-loaded saponified orange waste," J. Mater. Cycles Waste Manage., vol. 13, pp. 293-297, Dec. 2011.

[37] T. A. H. Nguyen et al., "Phosphorus elimination from aqueous solution using zirconium loaded okara as a biosorbent," Bioresour. Technol., vol. 170 , pp. 30-37, Oct. 2014

[38] T. A. H. Nguyen et al., "Adsorption of phosphate from aqueous solutions and sewage using zirconium loaded okara (ZLO): Fixed-bed column study," Sci. Total Environ., vol. 523, pp. 40-49, Aug. 2015.

[39] T. Nakajima, Deep Seawater Utilization, Tokyo, Japan: Midori Shobo, 2002.

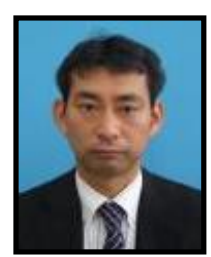

Takaaki Wajima was born in February 1976 in Saga Prefecture, Japan. He has been an Associate Professor in the Department of Urban Environment Systems, Graduate School of Engineering, Chiba University, Japan, since 2013. He received his bachelor's degree and master's degree in resource engineering from Kyoto University, Japan, in 1998 and 2000, respectively, and his $\mathrm{PhD}$ in environmental mineralogy and technology from Kyoto University, Japan, in 2004. His main PhD research theme was "microporous materials synthesized from paper sludge ash at low temperature, and their chemical mineralogy." In 2004, he moved to the Institute of Ocean Energy at Saga University to work as a postdoctoral researcher, and from 2007 to 2013 he was an Assistant Professor at Akita University, Japan. His main research interests are waste recycling, resource recovery, and environmental purification. 